\title{
Technology and Being: A Discussion of Their Metaphysical Significance
}

\author{
Theodore John Rivers \\ Independent, Forest Hills, USA \\ Email: trivers13@verizon.net
}

Received 7 January 2015; accepted 17 February 2015; published 30 March 2015

Copyright (C) 2015 by author and Scientific Research Publishing Inc.

This work is licensed under the Creative Commons Attribution International License (CC BY). http://creativecommons.org/licenses/by/4.0/

(c) (i) Open Access

\begin{abstract}
This paper discusses the relationship between various metaphysical ideas associated with technology and the concept of being, notably in reference to the becoming of being, which is a description for change. And change influences technology in many ways when expressed through the mode and manifestation of its being. As a mode of being, technology is the means or manner by which we do anything. Consequently, mode is an effect of action as well as a cause for other actions yet to occur. As a manifestation of being, technology becomes the predominant way in which humanity presents itself to the world. Since we have aligned our being with technology, and have even on many occasions sublimated ourselves to it, it may be argued that our relationship with technology is simply a revelation of our desire to be.
\end{abstract}

\section{Keywords}

\section{Technology, Metaphysics}

\section{An Introduction to Metaphysics}

Apart from the traditional branches of metaphysics associated with theology, cosmology, and psychology, as founded by the ancient Greeks, metaphysics has also been subdivided by the late Scholastics in the sixteenth century and later popularized by Christian Wolff in the eighteenth century into two categories: general and special metaphysics. General metaphysics (or ontology) deals with the broad questions of being (being as being), abstracted as a discipline dealing with properties and principles that presumably support an underlying basis to everything from sub-atomic particles to galaxies. Comparatively, the metaphysics that concerns the world we live in is known as special metaphysics which deals with particular or individual realms of being, usually divided into three topics: God, nature, and humanity, although these topics are not equal. In a general sense, metaphysics is the link between all the areas of philosophy and their applications. Apart from a universal an- 
thropocentrism, we may say that the predominant metaphysical topic in the ancient world emphasized nature and how it came into being (cosmology); in the medieval world, God and the relationship with humanity (theology); and in the modern world, humanity and the relationship with nature (psychology). Needless to say, metaphysics has evolved since its inception and has changed because of contributions by later thinkers, an idea we should keep in mind when considering technology.

Although the applications of technology have changed over time, it should be apparent, even on the simplest reflection, that technology not only concerns humanity as its primary agent, but also makes change the vehicle by which this occurs. Yet, applications in themselves do not explain the importance of technology, since technology is more than the practical applications of science, which is a modern, although limited definition. It is the means in which humanity utilizes various types of phenomena (natural and artificial) to achieve some purpose. (Arthur, 2009: pp. 29 and 50-51). It may be equated with a tool, machine, product, device, procedure, technique, method, organization, or rationale. Because the definition of technology is multifaceted, it may be described as a utilization mechanism. As a result, the more technology exerts a presence in the world, the more it acquires an influence. So much so, everything eventually becomes technologized, which is not an unusual statement at a time that has surrendered itself overwhelmingly to technology. Nevertheless, regardless of any moral implications, evidence must be presented if technology has any importance at all. If it is important, attempts should be made to indicate where this importance originates. And here is the essential question for our analysis: where does the being of technology in all its forms and expressions originate, and how does it relate to the world?

Because metaphysics deals with many concepts that relate to common human experience, it is a subject that has been used and abused since its inception (Pelletier, 1990: pp. 34-35) ${ }^{1}$. It may be used as a science of reality that corresponds to its original intent, but it may also be used as a worldview that is preparatory to religion. Even the description of being as a fundamental metaphysical term is ambiguous, and has been utilized, but not always defined, by many metaphysicians. Being may be defined as anything that is, which is a description of particular or individual things. Therefore, a being is a description for a distinct or distinguishable entity. All beings that do exist, but might not have existed, are contingent on the uncertainty of existence. A being that exists, but is not contingent on anything for its existence, would be a necessary being, and an example of a necessary being we call God or a god. But being may also be a definition of the underlying basis to anything, that is, being may not only define individual things, but also the essential nature to all things. Therefore, being in a limited sense relates to things that we can experience, but in an unlimited sense relates to the ground for everything that exists. And herein lies the complexity of metaphysics.

Since being is the main topic of metaphysics, it is applicable as a description to objects, things, or existents that are represented by $i t^{2}$. Although being is the basis for properties or attributes, it is not a property in itself. It is not anything in its being except a presence. Before being came to be, there was no being, and after being is no more, there will be no being. Being that is not yet being or has lost being is described as not-being (or non-being), which is a description of contingency that something may exist or did exist. To state it simply, being-as a description for what is-is another way of describing the presence of something, which in reference to technology concerns its origin, and its relationship to humanity and the world.

\section{The Becoming of Being as a Description for Change}

Metaphysics concerns what we can comprehend, or at the very least, proposes questions about the nature of things that seem to be comprehensible. The ancient topic of universality and particularity (or unity and plurality) so commonly associated with ancient Greek philosophy has been supplemented by topics that deal with the

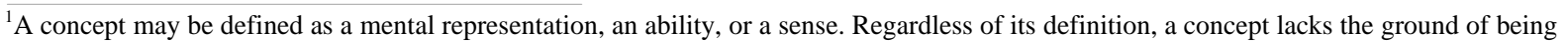
because it denotes an absence of concrete reality. Its relationship with being is revealed when it moves a being to action. This argument may be offered as a criticism of Plato's theory of forms in which perfect entities of imperfect earthly copies supposedly reside in an extraterrestrial realm detached from this world. The forms conceptualized by Plato became a basis for both physical bodies of real entities and spiritual entities (so-called immaterial substances). Hence, the argument concerning being as an equivalent of a body and being as a description of something bodiless goes back to Plato and the pre-Socratic philosophers. Whether or not a concept is innate or learned, we should agree that the nature of being that humans can know is limited to entities that are real, material, or present, a distinction that is relevant to the being of technology. In general, see Plato, Parmenides, 129a-135d, and Sophist, 246a-b.

${ }^{2}$ There is a difference of interpretation regarding the definition of objects and things. An object, such as an apple, is a thing, but a thing, such as God, may not be an object. There is a greater difference of interpretation regarding people, since it may be concluded that whatever type of being relates to a person's situation could be considered to be an object, such as another person, dead and living matter, tools, ideas, mathematics (concepts?), and the effects of imagination. This conclusion is highly suspect, and seems to beg the question, but a supporter of these kinds of objects is Jaspers, 1969: I, p. 47.
} 
transformation of metaphysics since the end of the Middle Ages. More than the distinction between general and special metaphysics that was popularized in the eighteenth century, metaphysics now concerns being's sublimation to motivations rarely emphasized in the past, motivations that are linked to humanity's innovative spirit, and especially to new ideas, new challenges, and new dangers associated with modernity, most notably with life characterized by a technological age. The driving force of modernity that centers on humanity's role in the world has replaced antiquity's pursuit of nature, and the medieval pursuit of theology. But it is also based on uncertainty about the meaning of being itself.

The coming into being, or becoming, is particularly relevant to metaphysics because it supplements the understanding of being that is. It is thought to be a process by which being may be the result, but traditionally becoming is perceived, from Parmenides to the present, as an inferior type of being because it is associated with change and not with permanence (or changelessness). Because becoming involves an act of engagement that manifests a process of doing, it allows becoming to lie at the threshold of being. Becoming signifies a blossoming into a presence that did not exist before. It signifies not only a coming into being, but also a modification of being that already exists. It is through this modification where technology is pertinent. Any activity by itself may not be an example of becoming, but it may be an example when it is affected by being, which is relevant to technology. Becoming implies imperfection, and imperfection presupposes attempts for improvement, regardless how they are achieved. Technology is built on these elementary ideas, at least initially, although many inventions and numerous innovations appeared without any practical effect, which seems to refute the myth that necessity is the mother of invention ${ }^{3}$.

Many things may be engaged in becoming if they change, such as flowing rivers, radiant stars, or human history. And history as we all know is defined by change, without which, it would not exist. It is also determined by time, the medium through which all human endeavors are revealed, regardless of how time's variants may be assessed. Although humanity is analyzed by metaphysics and revealed through history, it is also defined by the world that limits human choices. Because of time, the being of human beings is tied to a perception of the world's temporality. The question remains whether or not becoming is impacted by the passage of time, that is, whether the past and the future are real designations of time that have an influence on present time and the latter's relationship to being, rather than time variants signifying no more than arbitrary labels of a space-time continuum (Smart, 1963: pp. 132-142). But despite the interpretation of time's variants, it is becoming that has made technology important because it is both a cause for the transformation of the world that is evident in numerous ways as well as an effect of everything that follows.

Technology as a cause means that it is the agent by and through which a result is made. Since a cause may be defined as the motivation or purpose for doing something, it is projected into its effect that brings change into the world. Technology is the primary vehicle in which this change occurs. Such a phenomenon leaves a lasting impression of the changes that technology brings, that is, the more technology influences the world, the greater is its presence, and the greater is its presence, the more it influences the world. We make this observation knowing full well that technology is never neutral in its impact. It is either positive or negative depending on its application. And because of the non-neutrality of technology, there are some technologies that are controversial, especially in regard to nuclear technologies, in which positive applications concern nuclear energy whose use would eliminate the release of carbon dioxide into the atmosphere (greenhouse effect), and whose negative applications concern thermonuclear weapons, dirty bombs, and nuclear waste. Both the positive and negative applications of nuclear technologies changed the world and introduced new thresholds for the future. Similarly, any technology may be used reasonably or abused, but only research and experimentation over a long period of time would reveal its long-term consequences. The relationship between technology's presence and its influence, as discussed above, indicates that technology is both a mode and a manifestation of its being (Rivers, 2013: pp. 140-149).

\section{Technology as a Mode of Being}

Mode may be defined as a means of doing something, a manner of acting, a way of positing existence, a form or variety of a thing, or a demonstration of the individualization of a being, to name a few of its definitions. Since

\footnotetext{
${ }^{3}$ An invention may be defined as the creation of anything that did not exist before, and in order to have an effect on changing conditions an innovation may be defined as an invention newly applied. Although in many cases, necessity preceded invention, not every invention is the result of necessity. Two inventions that preceded necessity were the wheel and the automobile.
} 
mode initially is not dependent on anything, it is also not dependent on being, but is the result in which being is presented. Mode is not dependent on any preexisting condition thereof, whether technology or otherwise. Because it is a means of doing something, mode is both an effect of action, as well as a cause of other actions yet to occur. Mode is the manner how we create and change the world. It is the medium through which everything we do comes into being, including the being of technology. As we said above, mode is not predicated on anything, and because the means of doing anything concerns the performance of activities, in a sense a mode is a type of method.

Since method is a framework by which tasks may be completed, it is essentially concerned with improving those conditions that already exist. Although it usually concerns the same or similar manner of actions, which are derived from past actions, it may also relate to future ones. A method is dependent on human choices, and it demonstrates an engagement with the world that is conditioned by the choices already made that may also be projected into the future. Technology's mode is progressive, which indicates that there can be an addition or a design of some type that will push technology in a new direction. Technology's progressiveness infers that there will be improvements or advancements in the future when compared with the past. Even if this idea is not true in every case, it implies that the world will get better because of the use of technology. Despite its consequences, modernity is linked to the idea of progress that has been intensified with a perspective that is forwardly directed, historically related to Western civilization's innate progressiveness that developed during the European Middle Ages and is ubiquitous in the modern world (Benz, 1966: pp. 123-127).

As a mode of being, technology conveys an underlying mechanism to its presence, even if that presence is as simple as flaking stones in order to make stone tools, or smelting ore in order to make metal. The mechanism of technology's being is defined as soon as we act, which in turn leads to other applications that help to define future possibilities. In a sense, technology's mode signifies more than a simple form for the performance of tasks; it has become the embodiment of its entire bearing on the world, revealed in its being by means of the totality of energy, conception, and fulfillment of human creativity. At this point, we are not referring to the consequences of technology that we have mentioned elsewhere, but to the influence of technology in general.

If we understand mode as a way in which we express ourselves, then it lies at the foundation of human existence, making it similar in meaning to the description of human nature that allegedly concerns the essential aspects of human reality. Tied to our personality and linked to our humanity, technology as a mode of being is the way in which we present our being in the world. Because technology is essential to everything we do, we cannot be separated from its manifestations that show how we express ourselves in the world. Technology has become the dominant way in which we reveal being. Whether or not we reflect why we use technology as the means of doing anything, that is, as a mode of being, may be questionable, but we should be aware that when technology's presence increases so does its influence. Any increase in the application of technology may or may not be for the better, but that is not the point. Rather, the point is technology's continuous presence that has an influence on all our options.

\section{Technology as a Manifestation of Being}

Technology is also a manifestation of being, and a manifestation is indicative of the presence of something. It is proof of the reality that something exists. The image seen by means of a television, the sound of a radio, and the communicative link between people by a phone, all reveal that televisions, radios, and phones demonstrate the reality of their technologies. Manifestation is the revelation of the facticity of an existent. Since technology is essential to everything we do, a simple look at the world around us will demonstrate its truth: in order to clean our teeth, we use the technology of toothbrushes and toothpaste; in order to store human knowledge, we use the technology of printed books and computerized memory; in order to travel far and near, we use the technology of automobiles, trains, ships, and airplanes. And the list of other activities in which technology enables us to act is nearly endless.

Neither the result of compulsion mandated by being, as proposed by Heidegger, nor by determinism presumably aligned to some transcendental realm, as proposed by Dessauer, technology is the result of free choice (Heidegger, 1977: pp. 11-16 and 25-33; Dessauer, 1933: pp. 50-66) ${ }^{4}$. The manifestation of this revelation is

\footnotetext{
${ }^{4}$ This conclusion that technology is the result of free choice is similar, in part, to Ellul's understanding that technology is autonomous, at least in regard to values, but differs when he concludes that technology is self-determining, that its closed organization "permits it to be self-determinative independently of all human intervention” (Ellul, 1963: pp. 10-11).
} 
overwhelmingly apparent because the being of technology is brought into the world as a consequence of our own being. Because manifestation is proof of being, the manifestation of technology is the predominant means by which we relate to everything. Using an old term of metaphysics, technology may be perceived to be a new type of universality because it encompasses everything and embodies an inherent inclusiveness. Since manifestation concerns the unfolding of human reality, it discloses an openness to ourselves. A manifestation is an exposition of the workings of human ingenuity. Even in prehistory, the magnitude of technology's influence was evident, but this influence has intensified greatly, both in technology and in its organization, since the industrial revolution (Pollard, 1981: pp. 85-87 and 142-148; Stearns, 1993: pp. 5-7 and 11).

From simple tools to sophisticated machinery, from agriculture to artificial intelligence, from metallurgy to nanotechnology, from everyday living to space exploration, technology dominates the world, but we should remember that this domination is the result of what we choose. Although it may be inaccurate to describe domination as deterministic, nevertheless, after the fact, it may seem to be true, or at least that is Heidegger's conclusion referred to above. But the bases of all technologies are human beings who introduce into the world new and different phenomena that did not exist before.

Although the Greeks encouraged the study of being, they did not live in a culture that was predominantly technological. They gave themselves the opportunity to think about the nature of being and its relationship with the world because they were removed from what is now the ubiquity of technology. Nevertheless, an analysis of technology should point the way to its metaphysical foundation. It should demonstrate that in addition to the use of technology for human survival, it has become the main vehicle in which humanity acts and reacts with the world. Technology has become more than a formative way for our being in the world; it has been equated with the very expression of being itself, from the neurobiological analysis of our bodies to the astronomical analysis of the stars. We may conclude, therefore, that the being of humans and the being of the world are in a reciprocal relationship. This reciprocity indicates that the world, that is, the social context applicable within a cultural structure, is a creation of human ingenuity. The social context is natural because it is biologically derived, but the cultural structure is technological because it is superimposed upon it. This conclusion would infer that human society is a technological manifestation ${ }^{5}$.

If humans were not free to choose, not free to act, not free to bring change into the world, then technology would not exist. Not only is technology created by us, it is also intensified by its applications. What lies at the foundation to humanity and technology's presence is ontological freedom, that is, both are based on an openness to being that is the wellspring from which everything we do originates. Freedom brings possibilities into actuality. In addition to natural conditions that influence the earth's climate and weather, it is human activity that defines the world, as we know it. Notwithstanding, ontological freedom is both conditional and unconditional, that is, freedom is limited by the situations of the world that make it conditional, but because we cannot cease to be free, it is unconditional. Therefore, freedom is a paradox. It is within this paradox where all human creativity originates, of which technology is a major expression.

The essential characteristics of technology include its relationship to rationality, its demonstration of a process, and its embodiment of a method, all of which help to align technology with knowledge that in turn is used to create and change the world. For example, rationality allows us to confront the world as we interact with it. Its intended purpose is directed toward clearly defined goals that are derived from an openness to being. Above all, rationality allows us to make the best possible choice from a variety of choices. The idea that rationality is tied to ontological freedom is obvious, but before rationality can exist, freedom must preexist (Searle, 2001: pp. 22-24). Rationality, even technological rationality, is aligned to acting in certain ways that are thought to lead to purposeful activity. However, technology is more than applied knowledge or the practical applications of science. As described above, technology is the means in which humanity utilizes various types of phenomena (natural and artificial) to achieve some purpose.

Likewise, technology manifests a process in which one application leads to another. The accumulated effects

\footnotetext{
${ }^{5}$ If society is a description of a mutually shared association between individuals, this description does not explain either the notion of unity associated with these individuals or the result of cooperation evident in society. There must be some other mechanism in addition to social factors from which society originates. And it is the difficulty of identifying this mechanism that has led to many theories about the origin of society. More than biology, some type of interlocking association seems to define it. Regardless how we describe this association, society seems to reveal a technological affiliation. Therefore, the question remains that if society is a type of technology, it must be so by means of a practice, procedure, custom, or method, any one of which is originally the result of free choice. These ideas are merely preparatory to all types of social theories, from Comte to Martineau, from Weber to Durkheim, from Simmel to Parsons, and beyond. Reference should also be made to Ogburn, 1964: pp. 24-27.
} 
of technological innovations constitute a process that lends itself to knowing how to improve what is at hand by applying today's innovations to tomorrow's adaptations. Although process begins with inventions, it is innovations, not inventions, which extend the initial burst of creative inventive energy beyond their original intent. Technology and the knowledge associated with it indicate an involvement of doing, that is, an engagement indicative of its presence.

As discussed above, technology embodies a method that is used for the fulfillment of its tasks. Its method is not only a characteristic of technology, but it is also the result of the combined effects of its other characteristics. It serves as an artifice, and because a method is intended to improve the applications that already exist, it is indispensable to the underlying knowledge utilized by these applications. Nevertheless, technology does not innately possess only one method expressive of its being, but several. These methods allow technology to be introduced, and when applied, they facilitate the realization of possibilities.

All of these characteristics help us to understand the metaphysical background of technology. Since being lies at the foundation of what a thing is, it is the focal point of any metaphysical analysis that is related to its phenomena. Although phenomena are helpful in understanding the nature of being, they are auxiliary to being's underlying presence. Technology is a bringing forth into being, but its bringing forth is an artificiality. This is to say that although technology is not ontologically essential, it is nonetheless the way in which we apply our being. It does not originate in being, but from being's application in the world. Since the mode of anything is aligned with its presence, mode as the nature of a thing projects what that thing is. When expressing this idea technologically, we can say that technology's mode is evident in its manifestation, that is, its nature indicates its presence that is revealed through its applications.

Like ontological freedom, technology is paradoxical in relationship to being. In fact, anything that is described as ontological must in some way be indispensable to or be derived from being, but technology's being must originate somewhere else. Although technology is conditioned by the same designation of presence, in which its products, or procedures, or organizations come into the world, it is not a condition of being. This is to say that although technology is dependent on being, it is not an attribute of it. As already discussed, technology is not the result of compulsion mandated by being (as introduced by Heidegger), nor by determinism aligned to some transcendental realm (as introduced by Dessauer), but the result of free expression. If we were compelled, we would not be responsible for anything we do. The same objection also pertains to determinism derived from some transcendental realm.

As far as the world is concerned, it is us who are its makers. The world, which is to be distinguished from nature, exists because we do, that is, the world is the result of our presence. If we like or dislike the world we find ourselves in, it is because people have made it that way. Because the world is expressive of the human condition that is defined through ontological freedom, it presents itself as a fact, and it is this fact that is the cause of the world's reality. The latter is merely a reflection of what we do with being. The present reflects the facts that are grounded in being, and from which reality is made evident. Therefore, reality mimics the facticity of the world that ontological freedom creates, and that in turn enables freedom to be exercised in making the world. Ontological freedom that is connected to the relativity of change will still exist regardless of the conditions of the world, and when the world changes, the exercise of freedom changes with it.

Within the context of ontological freedom that has given reality to the world, technology's applications may be equated with many conditions, which include circumstance, production, innovation, ingenuity, and progress, any one of which is indicative of technology's manifestation of being, but the primary importance of technology is its ability to change the world, which assumes that changes are for the better. Because being is shaped and modified by the world, the engagement of technology is always concerned with doing, but the doing of anything is secondary to the primary status of being, which means that for anything to be, it must be involved with doing. In regard to technology, its being is dependent on the development or fulfillment of its becoming. Technology is not fixed by time, but uses time to change. It has come into existence because it is not set by time, which enables technology to be projected into the future. Since we have aligned our being with technology, we can say that any action undertaken by means of technology is essentially our desire to be.

\section{Technology and the Becoming of Being}

The becoming of being deals with more than a concern about desire. It deals with the conditions that repeatedly manifest themselves from the presence of being itself. Etymologically, the verb to become means to be made, to 
spring forth, to come into existence, or to come to be, and it acquires a special significance when referring to humans. We may speak about other beings becoming, such as butterflies pupating or seeds germinating, but they lack an awareness that makes existence pertinent, conditions that are perceptive to being in general, either by way of a sensitivity to change, or by means of a consciousness of a transformation. Although other beings mature because they grow older, or continue because they propagate, or adapt because they evolve, in what sense do they become? In what sense do these other beings manifest a coming into being in relationship to being itself? It is with an understanding of being engaged with life's conditions that there is becoming. If being as being is static, then the becoming of being is dynamic. If the becoming of being transforms itself into being, then it must give itself to it. Therefore, it is with being as an end in itself that becoming has meaning. And the nature of becoming is evident through the modification of ourselves that is reflective of our efforts, laid out from beginning to end by means of our doing. Action is the means by which being is revealed, since our doing of anything, as we mentioned above, is essentially our desire to be.

If we were to disregard the fundamental ideas of metaphysics as established by the ancient Greeks, we could devise a new (although some might say an inaccurate) interpretation of being. If we accept the ideas of the Greeks that being's permanence can only be associated with some type of first cause that is unchanging, immutable, and eternal, then change must be associated with an inferior type of being. If the permanence of being is considered to be its only perception, then all other perceptions must be denied as true. Such an interpretation ignores the place of becoming within being itself. If we affirm the necessity of humanity for the creation of the world, then we must support the importance of becoming. And it is with becoming that desires are projected.

But becoming must not be confused with technology's being or the being of technical objects. It is true to conclude that humanity's becoming is the way in which humans express themselves, but it is not true to conclude that technology and technical objects have their own becoming innate to themselves. Humans become, but technology and technical objects do not. When technology and technical objects change because of human effort, either because they have been improved or replaced, it is humanity that is the agency of change. Although technology is the object, humanity is the subject ${ }^{6}$.

Regardless how we define desire, we should all agree that a desire concerns an action or feeling, whether or not it is rational. Although there may be no good reason to act if there is no desire, a desire is the result of a person's whole being, not a mental state that produces action or is intended to produce it. There might be other causes for actions in addition to desire, but we are not concerned about desires that are pursued exclusively for themselves. If a desire is wanted for itself, then it becomes an end in itself; but if it is wanted for what it can do, then it becomes the means to an end. And technology, at least in its modern version, emphasizes means over ends.

In general, to desire anything is a wish to acquire what we do not have. Consequently, we may say that desire is noted for its lack of being. Because it is the desire to make all manner of things through our effort, it is our choices, decisions, and applications of technology that make anything evident. Whether planned theoretically or enacted practically, technology always demonstrates a relationship with the world. The desire to apply and facilitate technology reveals the type of world we expect to have, but technology's presence is far more extensive than we might assume because its use by methodical or material means has influenced all our options. It has become the principal means by which we create, manipulate, and change the world.

\section{Conclusion}

It is well known that we have sublimated our being to technology. In fact, it is not so much that technology is equated with our being, but the reverse: our being is equated with technology. Regardless of how we interpret being, it is apparent that we have submitted to an artificiality of our own making. Whenever and however we express our being, we do so by means of technology. This conclusion is obvious, especially when we consider

\footnotetext{
${ }^{6}$ Although our being potentially contains within itself whoever we will become, it is a misunderstanding to extend this ability to technical objects. Therefore, it is inaccurate to conclude that technical objects in any way are involved in their own becoming, which is a conclusion of Simondon, 1958: p. 20 (“L’objet technique est ce qui n’est pas antérieur à son devenir, mais présent à chaque étape de ce devenir”), which he later (pp. 155-156) attributes not to the actualization of virtual realities, but to the potentialities of the system from which technology springs forth. To which we should add that if humans are not the creators of technology, how could technical objects, which are human creations, be the creators of themselves? Simondon's conclusion is parallel to Heidegger's interpretation of "ready-to-hand" (zuhanden in German), which confuses the usefulness of a thing (an object) with its presence, that is, whatever a thing is said to be "ready-to-hand" is simply a description for a thing existing so that it may be ready to be used. Contrary to Heidegger, "ready-to-hand" must follow, not precede being. See Harman, 2002: pp. 180-189.
} 
that technology is essential to human survival, but human reality would not exist without technology. Like ontological freedom, technology is in a paradoxical relationship with being. It is dependent on being in order to be brought into the world, and is even a manifestation of it, but it is not essential to being's maintenance. Technology is a result of being, but it is not a quality, attribute, or property of it. Although it is the result of being's application, it does not originate within being itself. We may extend this interpretation to humanity because the latter is characterized by uncertainty, indecision, unpredictability, even ignorance, to say nothing of mistrust and disbelief.

We should also note the relationship between knowledge and/or action and being. Simply stated, in order to know or do anything, we first have to be. And the being we can become will always surpass what we can know or do. Our being is an indication of who we have become, but since we are continually engaged in the act of becoming, we are incomplete until we have finished the process, that is, until we have achieved an essence, which may be defined as the ground to existence (Avicenna), or simply the totality of an individual existence (Sartre). Although becoming is a process to which being is subject, it is now through technology that we are involved in this process. The result is an artificiality that dominates humanity, an artificiality that does more than struggle with nature. It is an artificiality that struggles with itself.

Fundamentally, in order for our being to be and in order for us to modify our natural tendencies, even those that create and innovate technology, we have to will the being we wish to be. Like any other desire, technology is indicative of this will. And what is any will in the first place if it does not describe a desire to be? We can answer this question by saying that the will as the driving force of a person must will itself in order to be. The will to be is really the will's ability to will itself, which is similar to Nietzsche's will to power in which the will's ability to have more will is the means that intensifies being. Technology has become the means to the will to power. Whether or not this will makes technology good or evil, whether or not it has beneficial or harmful consequences, whether or not it is applied carefully or recklessly does not displace the importance of technology within the realm of being. The world as we know it has been transformed. Whether we like it or not, the metaphysical significance of being is now revealed through technology.

\section{References}

Arthur, W. B. (2009). The Nature of Technology: What It Is and How It Evolves. New York: Free Press.

Benz, E. (1966). Evolution and Christian Hope: Man's Concept of the Future from the Early Fathers to Teilhard de Chardin. H. G. Frank (Trans.). Garden City: Doubleday.

Dessauer, F. (1933). Philosophie der Technik. Das Problem der Realisierung (3rd ed.). Bonn: Friedrich Cohen Verlag.

Ellul, J. (1963). Technological Order. In C. F. Stover (Ed.), The Technological Order: Proceedings of the Encyclopaedia Britannica Conference (pp. 10-37). Detroit: Wayne State University Press.

Harman, G. (2002). Tool-Being: Heidegger and the Metaphysics of Objects. Chicago: Open Court.

Heidegger, M. (1977). The Question Concerning Technology and Other Essays. W. Lovitt (Trans.). New York: Harper \& Row.

Jaspers, K. (1969). Philosophy. E. B. Ashton (Trans.), (3 Vols). Chicago: University of Chicago Press.

Ogburn, W. F. (1964). On Culture and Social Change: Selected Papers. O. D. Duncan (Ed.). Chicago: University of Chicago Press.

Pelletier, F. J. (1990). Parmenides, Plato, and the Semantics of Not-Being. Chicago: University of Chicago Press.

Pollard, S. (1981). Peaceful Conquest: The Industrialization of Europe, 1760-1970. Oxford: Oxford University Press.

Rivers, T. J. (2013). Technology as a Mode and Manifestation of Being: An Assessment of Its Applications. Advances in Historical Studies, 2, 140-149. http://dx.doi.org/10.4236/ahs.2013.23018

Searle, J. R. (2001). Rationality in Action. Cambridge, MA: MIT Press.

Simondon, G. (1958). Du mode d'existence des objets techniques. Paris: Aubier.

Smart, J. J. C. (1963). Philosophy and Scientific Realism. London: Routledge \& Kegan Paul.

Stearns, P. N. (1993). The Industrial Revolution in World History. Boulder: Westview Press. 